\title{
Hepatotoxicity Caused by Repeated and Subchronic Pulmonary Exposure to Low-Level Vinyl Chloride in Mice
}

\author{
Li-Te Chang ${ }^{1,+}$, Yueh-Lun Lee ${ }^{2,+}$, Tzu-Hsuen Yuan ${ }^{3}$, Jer-Hwa Chang ${ }^{4,5}$, Ta-Yuan Chang ${ }^{6} \mathbb{D}$, Chii-Hong Lee ${ }^{7}$, \\ Kin-Fai Ho ${ }^{8,9}$ and Hsiao-Chi Chuang $4,10,11, *$ D
}

1 Department of Environmental Engineering and Science, Feng Chia University, Taichung 407, Taiwan; ltechang@fcu.edu.tw

2 Department of Microbiology and Immunology, School of Medicine, College of Medicine, Taipei Medical University, Taipei 11031, Taiwan; yllee@tmu.edu.tw

3 Department of Health and Welfare, College of City Management, University of Taipei, Taipei 10617, Taiwan; jamesfisher955@yahoo.com.tw

4 School of Respiratory Therapy, College of Medicine, Taipei Medical University, Taipei 11031, Taiwan; jerhwa@tmu.edu.tw

5 Department of Internal Medicine, Division of Pulmonary Medicine, Wan Fang Hospital, Taipei Medical University, Taipei 11031, Taiwan

6 Department of Occupational Safety and Health, College of Public Health, China Medical University, Taichung 404, Taiwan; tychang@mail.cmu.edu.tw

7 Department of Pathology, Taipei City Hospital, Heping Fuyou Branch, Taipei 100, Taiwan; b8301130@tmu.edu.tw

8 Jockey Club School of Public Health and Primary Care, The Chinese University of Hong Kong, Hong Kong, China; kfho@cuhk.edu.hk

9 Shenzhen Municipal Key Laboratory for Health Risk Analysis, Shenzhen Research Institute, The Chinese University of Hong Kong, Shenzhen 518172, China

check for

updates

Citation: Chang, L.-T.; Lee, Y.-L.; Yuan, T.-H.; Chang, J.-H.; Chang, T.-Y.; Lee, C.-H.; Ho, K.-F.; Chuang, H.-C. Hepatotoxicity Caused by Repeated and Subchronic Pulmonary Exposure to Low-Level Vinyl Chloride in Mice. Atmosphere 2021, 12, 596. https:// doi.org/10.3390/atmos12050596

Academic Editor: Daniele Contini

Received: 9 April 2021

Accepted: 30 April 2021

Published: 4 May 2021

Publisher's Note: MDPI stays neutral with regard to jurisdictional claims in published maps and institutional affiliations.

Copyright: (c) 2021 by the authors. Licensee MDPI, Basel, Switzerland. This article is an open access article distributed under the terms and conditions of the Creative Commons Attribution (CC BY) license (https:/ / creativecommons.org/licenses/by/ $4.0 /)$.
10 Department of Internal Medicine, Division of Pulmonary Medicine, Shuang Ho Hospital, Taipei Medical University, New Taipei City 220, Taiwan

11 Cell Physiology and Molecular Image Research Center, Wan Fang Hospital, Taipei Medical University, Taipei 11031, Taiwan

* Correspondence: r92841005@ntu.edu.tw; Tel.: +886-2-27361661 (ext. 3512); Fax: +886-2-27391143

+ These authors contributed equally to this study.

Abstract: Vinyl chloride (VC) is classified as a group 1 carcinogen to humans by the International Agency for Research on Cancer, and inhalation is considered to be an important route of occupational exposure. In addition, increasing numbers of studies have observed adverse health effects in people living in the vicinity of petrochemical complexes. The objective of this study was to investigate the adverse in vivo health effects on the lungs and liver caused by pulmonary exposure to lowlevel VC. BALB/c mice were repeatedly intranasally administrated $50 \mu \mathrm{L} /$ mouse VC at 0,1 , and $200 \mathrm{ng} / \mathrm{mL}$ (5 days/week) for 1, 2, and 3 weeks. We observed that exposure to 1 and $200 \mathrm{ng} / \mathrm{mL}$ VC significantly increased the tidal volume $(\mu \mathrm{L})$. Dynamic compliance $\left(\mathrm{mL} / \mathrm{cmH}_{2} \mathrm{O}\right)$ significantly decreased after exposure to $200 \mathrm{ng} / \mathrm{mL}$ VC for 3 weeks. Total protein, lactate dehydrogenase (LDH), and interleukin (IL)-6 levels in bronchoalveolar lavage fluid (BALF) significantly increased after exposure to $200 \mathrm{ng} / \mathrm{mL}$ VC for 2 and/or 3 weeks. Significant decreases in 8-isoprostane and caspase- 3 and an increase in IL-6 in the lungs were found after VC exposure for 2 and/or 3 weeks. We observed that aspartate aminotransferase (AST), alkaline phosphatase (ALKP), albumin (ALB), and globulin (GLOB) had significantly increased after three weeks of VC exposure, whereas the ALB/GLOB ratio had significantly decreased after 3 weeks of exposure to VC. IL-6 in the liver increased after exposure to $1 \mathrm{ng} / \mathrm{mL}$ VC, but decreased after exposure to $200 \mathrm{ng} / \mathrm{mL}$. IL- $1 \beta$ in the liver significantly decreased following exposure to $200 \mathrm{ng} / \mathrm{mL} \mathrm{VC}$, whereas tumor necrosis factor (TNF)- $\alpha$ and caspase- 3 significantly increased. Hepatic inflammatory infiltration was confirmed by histological observations. In conclusion, sub-chronic and repeated exposure to low levels of VC can cause lung and liver toxicity in vivo. Attention should be paid to all situations where humans are frequently exposed to elevated VC levels such as workplaces or residents living in the vicinity of petrochemical complexes. 
Keywords: air pollution; apoptosis; inflammation; liver function; lung function; oxidative stress

\section{Introduction}

Numerous volatile organic compounds (VOCs) are confirmed, and many more are suspected to be, carcinogens [1,2]. Recent reports have indicated that adverse health effects occurred in nearby residents after exposure to air pollution emitted from oil refineries and petrochemical plants [3-5], including an increase in the risk of developing all cancers, brain cancer, and respiratory disorders [6,7]. Hepatotoxicity is often observed after occupational exposure to VOCs in vivo [8], and after environmental exposure by school-aged children living in the vicinity of a petrochemical complex [9]. However, the effects of low-level environmental exposure to VOCs on human health in the vicinity of petrochemical complexes are still unclear.

Halogenated VOCs, such as vinyl chloride (VC), are classified as a group 1 carcinogen to humans by the International Agency for Research on Cancer (IARC) [10], and inhalation is considered to be an important route of occupational exposure. VC is primarily used to produce polyvinyl chloride (PVC), and workplaces for PVC fabrication processes are the main sites of occupational exposure. The American Conference of Government Industrial Hygienists (ACGIH) threshold limit value (TLV) for VC is 1 ppm [11]. Notably, VC has been reported to be measurable in the atmosphere in the vicinity of petrochemical complexes [12]. However, the resultant health impacts are still poorly understood.

Occupational exposure to VC is associated with lung-to-systemic effects in humans. An in vivo study indicated that liver inflammation and injury occurred after $24 \mathrm{~h}$ of exposure to chloroethanol in C57Bl/6J mice [13]. The renal system is the primary pathway for excretion after low-dose exposure, whereas exhalation of unmetabolized VCM is achieved by higher doses with enzyme saturation [14]. The liver is a detoxifying organ following exposure to toxic agents. Cytochrome P450 2E1 (CYP2EI) is able to covert VC into the active metabolite, 2-chloroethylene oxide. However, this VC metabolite is able to covalently bind to nucleic acids and proteins, leading to genotoxicity in the liver (Easter and Von Burg, 1994). A study has shown that VC exposure is associated with chromosomal damage in vinyl chloride-exposed workers [15]. Exposure to VC in air at concentrations between $0.8 \%$ and $15.0 \%$ caused mutagenicity in H2E1 cells, suggesting saturation of metabolic activation [16]. Next-generation sequencing has revealed that $\mathrm{N}(2), 3-\varepsilon \mathrm{G}$ could be a biologically important lesion and may have a functional role in VC-induced or inflammation-driven carcinogenesis in vivo [17]. Collectively, genotoxicity and inflammation are important biological outcomes after VC exposure.

Residents living in the vicinity of petrochemical complexes had smaller increases in life expectancy over time than did the non-petrochemical reference group [18]. The reduction in life expectancy for residents living in the vicinity of petrochemical complexes may be associated with pollutants emitted by certain industries. In Taiwan, a previous report indicated that the average concentration was $10.3 \mathrm{ppb}$, and the maximum concentration was $30 \mathrm{ppb}$ in a primary school approximately $1 \mathrm{~km}$ from a petrochemical complex [19]. The exposure level is equal to $10.3 \mathrm{mg} / \mathrm{kg}$ of body burden on average. Indeed, petrochemical industries are an important emission source for a wide range of chemical substances such as VC. The objective of this study was to investigate the adverse health effects on the lungs and liver that occur after pulmonary exposure to low levels of VC in vivo.

\section{Materials and Methods}

\subsection{Animals}

Six-week-old male BALB/c mice were obtained from BioLASCO (Taipei, Taiwan). The mice were housed at $22 \pm 2{ }^{\circ} \mathrm{C}$ and $55 \% \pm 10 \%$ relative humidity (RH) under a $12 / 12$-h light/dark cycle. This study was approved by the ethics review committee of the Laboratory Animal Center (no. LAC-2014-0300) at Taipei Medical University (Taipei, Taiwan). 


\subsection{Experimental Design and VC Exposure}

The experimental design is shown in Figure 1. The mice were randomly divided into nine groups for three time points: 1 week (groups 1, 2, and 3), 2 weeks (groups 4, 5, and 6), and 3 weeks of exposure (groups 7, 8, and 9). Mice at each time point were intranasally administered $50 \mu \mathrm{L}$ of VC (Sigma, St. Louis, MO, USA) prepared in phosphate-buffered saline (PBS) at 0,1 , and $200 \mathrm{ng} / \mathrm{mL}$ once a day for 5 days per week for 1, 2, and 3 weeks. The low level of VC $(1 \mu \mathrm{g} / \mathrm{mL}(\mathrm{ppb}))$ and high level $(200 \mu \mathrm{g} / \mathrm{mL}(\mathrm{ppb}))$ were referenced from the highest ambient level in the vicinity of petrochemical complexes and the threshold limit value (TLV) for VC [11]. Administration was conducted under light anesthesia (2\% isoflurane) using a rodent anesthesia machine (Northern Vaporiser; Skipton, UK). The pulmonary function of mice was measured, followed by euthanization. Bronchoalveolar lavage fluid (BALF) and whole blood were collected, and lung and liver tissues were snap-frozen in liquid nitrogen or fixed in $4 \%(\mathrm{~m} / \mathrm{v})$ paraformaldehyde for histological analyses. There were six mice in each group. The sample preparation has previously been described [20].

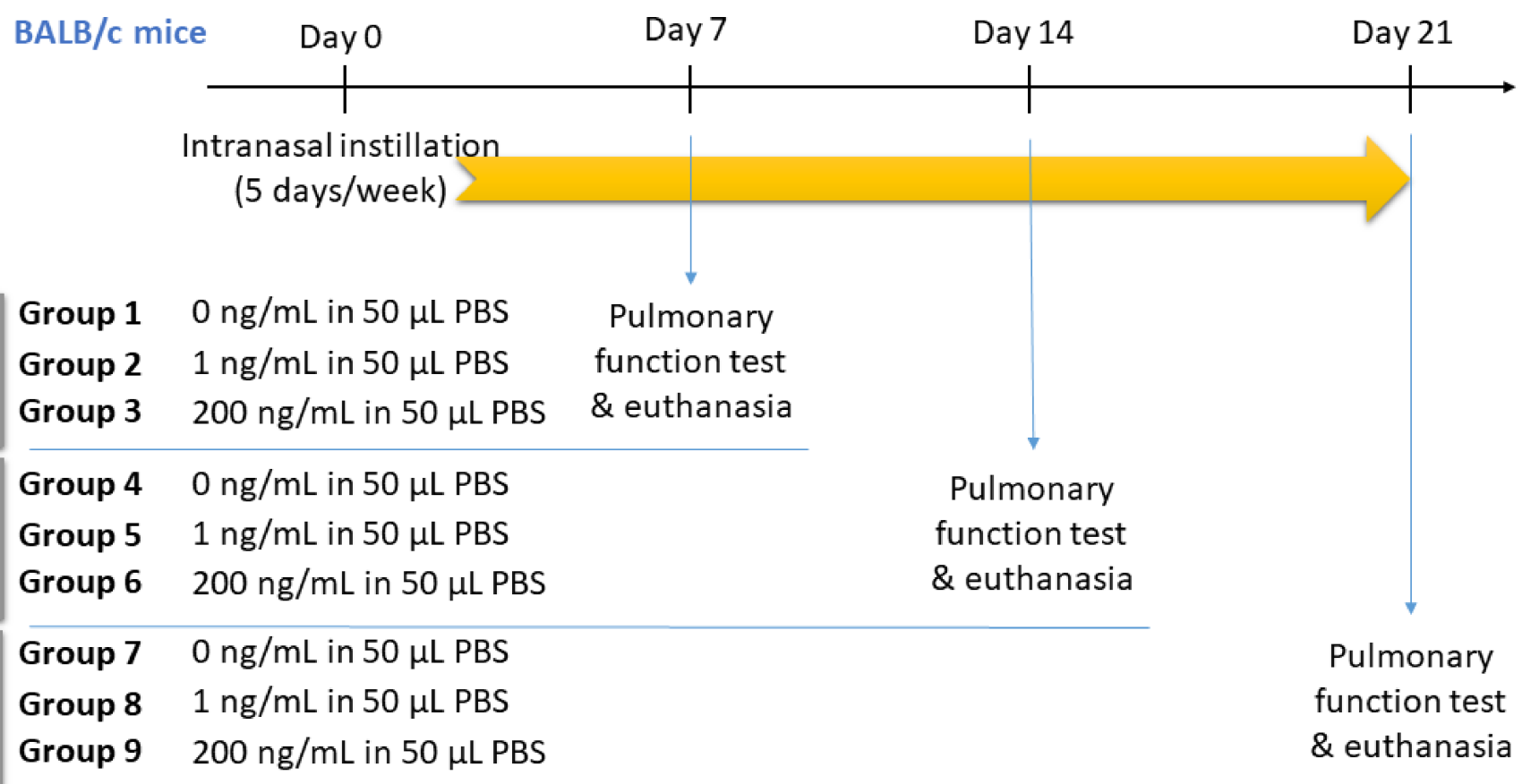

Figure 1. Illustration of the experimental design. Mice were randomly divided into 9 groups for 3 time points: 1 week (groups 1, 2, and 3), 2 weeks (groups 4, 5, and 6) and 3 weeks of exposure (groups 7, 8, and 9). Mice in each time point were intranasally administrated $50 \mu \mathrm{L}$ of vinyl chloride (VC) at 0,1 , and $200 \mathrm{ng} / \mathrm{mL} 1$ time per day, 5 days per week for 1,2 , and 3 weeks. Pulmonary function tests and euthanasia were conducted at the end of weeks 1,2 , and 3. $n=6$ per group.

\subsection{Pulmonary Function Test}

Pulmonary function was monitored by a tracheostomy tube with a ventilator (MicroVent Prenatal Mouse Ventilator, Harvard Apparatus, Holliston, MA, USA) under light anesthesia ( $2 \%$ isoflurane) using a rodent anesthesia machine. Raw respiration signals were interfaced with a physiological recording system (MP150, Biopac Systems, Goleta, CA, USA) using DA100C and ECG100C-MRI amplifiers. Pulmonary function parameters were analyzed using AcqKnowledge vers. 4.2.1 (Goleta, CA, USA).

\subsection{Biochemical Evaluation}

Whole-blood samples from each mouse was collected by intracardiac puncture followed by centrifugation at $2000 \times g$ for $20 \mathrm{~min}$ to separate the serum. Biochemical results, including alanine transaminase (ALT), aspartate aminotransferase (AST), alkaline phosphatase (ALKP), total bilirubin (TBIL), albumin (ALB), globulin (GLOB), and the 
ALB/GLOB ratio, were determined using an IDEXX VetTest Chemistry Analyzer (Westbrook, ME, USA).

\subsection{Permeability and Cytotoxicity of the Lungs}

BALF samples were collected from each mouse followed by centrifugation at $1500 \times g$ to separate the supernatant. Levels of total protein (BioRad, Hercules, CA, USA) and lactic dehydrogenase (LDH; Thermo Scientific, Waltham, MA, USA) were determined in BALF samples according to the manufacturers' instructions.

\subsection{Oxidative Stress, Inflammation, and Apoptosis in the Lungs and Liver}

Lung and liver tissues were homogenized in RIPA buffer (Sigma) with a Complete ${ }^{\mathrm{TM}}$ protease inhibitor (Roche Diagnostics, Basel, Switzerland) according to the manufacturers' instructions. 8-Isoprostane (Cayman, Ann Arbor, MI, USA), interleukin (IL)-6 (R\&D, Minneapolis, MN, USA), caspase-3 (Cayman), IL-1 $\beta$ (R\&D), and tumor necrosis factor (TNF)- $\alpha$ activities in tissue lysates were determined in accordance with the manufacturer's instructions. Data obtained from lung and liver tissue lysates were normalized by the total protein.

\subsection{Hematoxylin and Eosin (HEE) Staining}

Fixed tissues were embedded in paraffin, sectioned, and stained with H\&E in accordance with standard protocols. Samples were histologically examined by a pathologist (CHL).

\subsection{Statistical Analysis}

Data are presented as the mean \pm standard deviation (SD). A one-way analysis of variance (ANOVA) with Tukey's post-hoc test was used for comparison among multiple values. Statistical analyses were performed using GraphPad vers. 5 (San Diego, CA, USA) for Microsoft Windows [21]. The level of significance was set to $p<0.05$.

\section{Results}

\subsection{Pulmonary Function}

Alterations in the tidal volume and dynamic compliance of mice after VC exposure over 3 weeks are shown in Figure 2. We observed that 3-week exposure to VC at 1 and $200 \mathrm{ng} / \mathrm{mL}$ increased the tidal volume $(\mu \mathrm{L})$ compared to 1 -week exposure $(p<0.05)$. The dynamic compliance $\left(\mathrm{mL} / \mathrm{cmH}_{2} \mathrm{O}\right)$ continuously decreased with $200 \mathrm{ng} / \mathrm{mL}$ VC exposure, and reached a statistical difference after 3 weeks $(p<0.05)$.
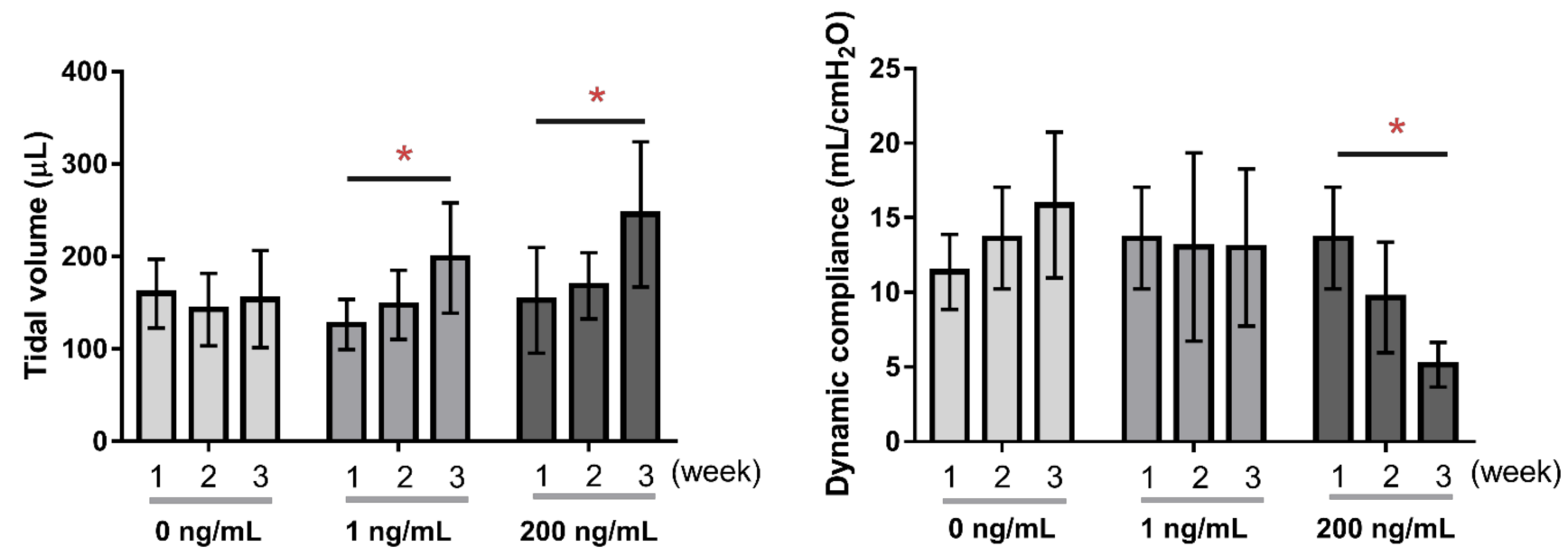

Figure 2. Alterations in the tidal volume and dynamic compliance of mice after vinyl chloride (VC) exposure. ${ }^{*} p<0.05$ compared between weeks at the same concentration. 


\subsection{Lung Injury Due to VC Exposure}

Figure 3 shows the levels of markers for lung injury in BALF and lungs of mice after VC exposure. We observed that 3-weeks exposure to VC at $200 \mathrm{ng} / \mathrm{mL}$ significantly increased total protein levels of BALF ( $p<0.05$; Figure 3a). Levels of LDH in BALF increased after $200 \mathrm{ng} / \mathrm{mL}$ VC exposure for 3 weeks $(p<0.05)$. We further found that IL-6 had significantly increased with $1 \mathrm{ng} / \mathrm{mL}$ of VC exposure for 2 and 3 weeks $(p<0.05)$ and $200 \mathrm{ng} / \mathrm{mL}$ of VC exposure for 3 weeks $(p<0.05)$. Next, we analyzed the effects of VC on lung tissues (Figure $3 \mathrm{~b})$. We observed that VC at $1 \mathrm{ng} / \mathrm{mL}$ decreased levels of 8 -isoprostane $(p<0.05)$, especially at 3 weeks, in a stepwise manner. IL-6 significantly increased after exposure to $\mathrm{VC}$ at $200 \mathrm{ng} / \mathrm{mL}$ for 2 and 3 weeks $(p<0.05)$. The level of caspase- 3 had significantly increased after exposure to VC at 1 and $200 \mathrm{ng} / \mathrm{mL}$ for 2 and 3 weeks $(p<0.05)$.

(a)

(b)
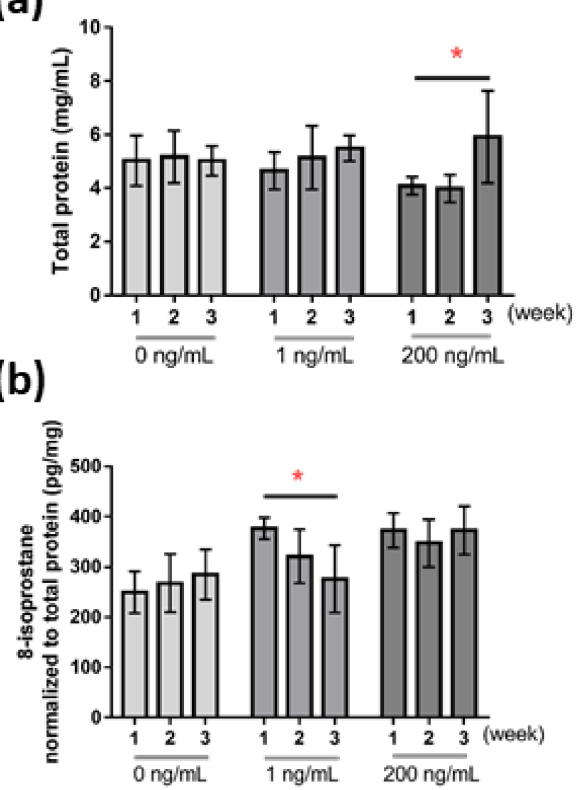
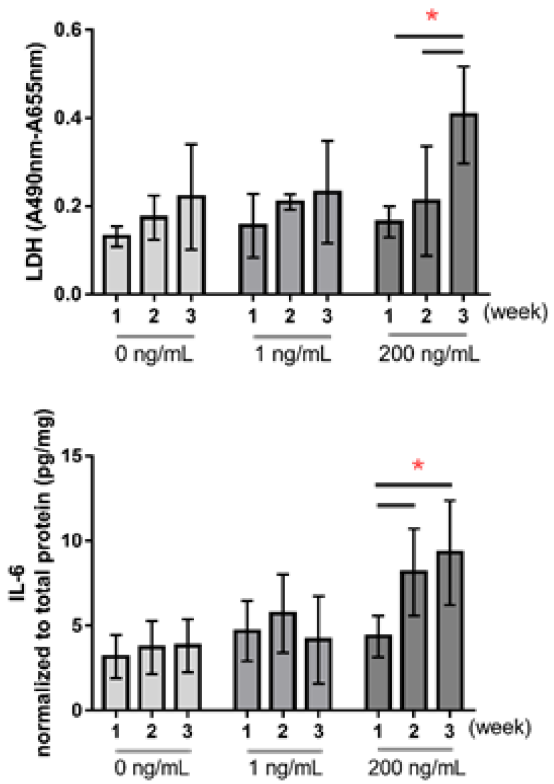
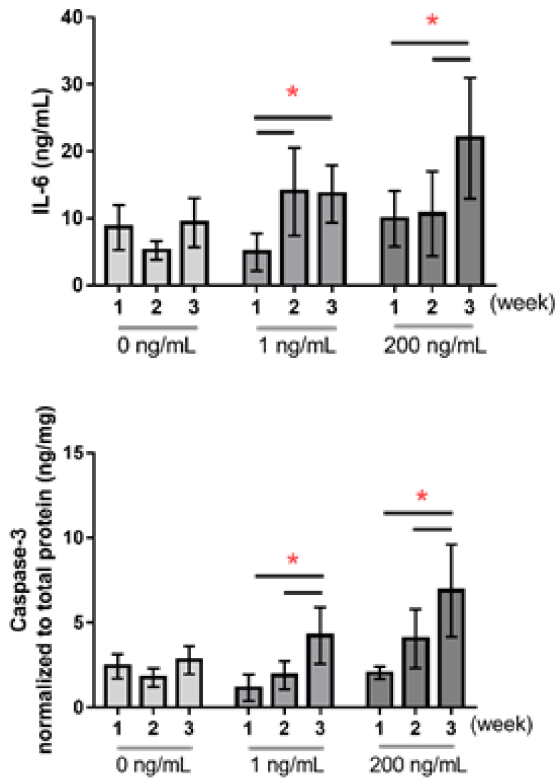

Figure 3. Levels of (a) total protein, lactate dehydrogenase (LDH), and interleukin (IL)-6 in bronchoalveolar lavage fluid (BALF) and (b) 8-isoprostane, IL-6, and caspase-3 in the lungs after vinyl chloride (VC) exposure. ${ }^{*} p<0.05$ compared between weeks at the same concentration.

\subsection{Alterations in Liver Function Biochemistry}

Figure 4 shows biochemical levels of whole blood, which are indicators for liver function. We observed that AST levels had significantly increased with 1 and $200 \mathrm{ng} / \mathrm{mL}$ VC exposure for 3 weeks $(p<0.05)$. ALKP had significantly increased after 3 weeks of exposure to VC at $200 \mathrm{ng} / \mathrm{mL}(p<0.05)$. Levels of ALB and GLOB had significantly increased following exposure to $1 \mathrm{ng} / \mathrm{mL}$ VC for 3 weeks $(p<0.05)$. However, the ALB/GLOB ratio had significantly decreased after 3 weeks of exposure to $200 \mathrm{ng} / \mathrm{mL} \mathrm{VC}(p<0.05)$.

\subsection{Liver Injury Due to VC Exposure}

Figure 5 shows levels of markers of liver injury of mice after VC exposure. We observed that IL-6 had significantly increased after $1 \mathrm{ng} / \mathrm{mL}$ VC exposure for 2 weeks $(p<0.05)$. However, levels of IL- 6 and IL-1 $\beta$ had significantly decreased following $200 \mathrm{ng} / \mathrm{mL}$ VC exposure for 2 and / or 3 weeks $(p<0.05)$. Levels of TNF- $\alpha$ and caspase- 3 were significantly increased by exposure to $200 \mathrm{ng} / \mathrm{mL} \mathrm{VC}$ for 2 and 3 weeks $(p<0.05)$. As to histology, we observed inflammatory cell infiltration in the liver after $200 \mathrm{ng} / \mathrm{mL}$ VC exposure for 3 weeks (Figure 5, arrow points). 

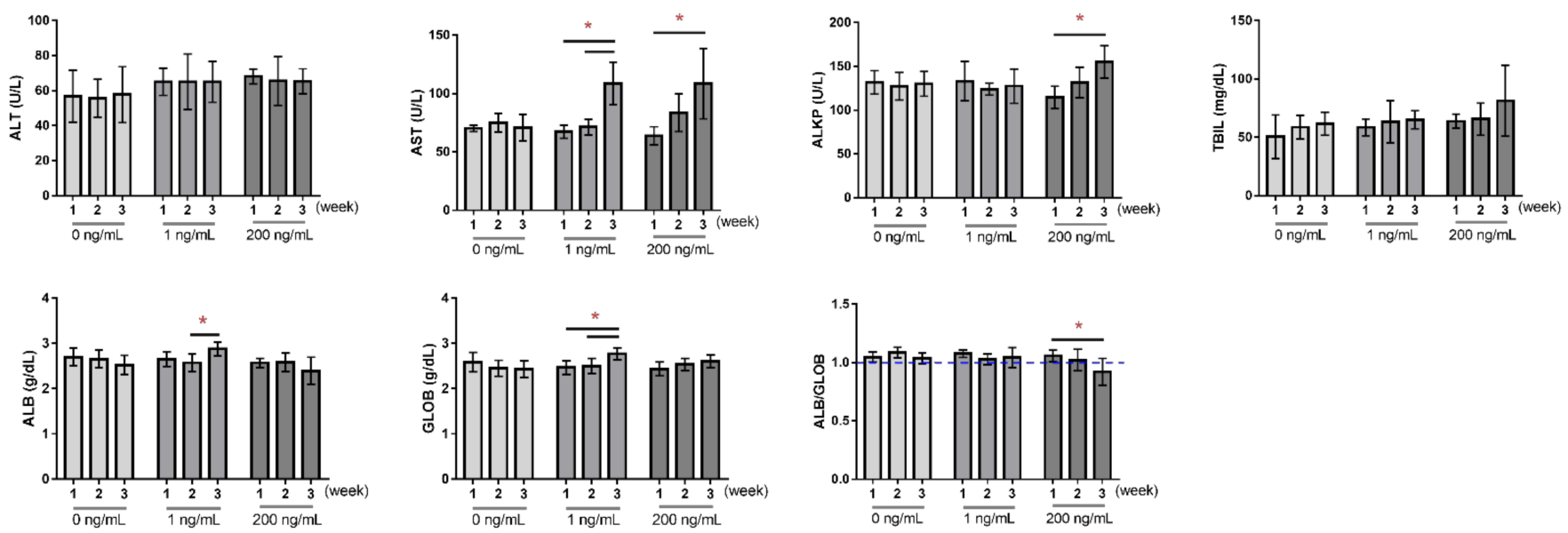

Figure 4. Levels of biochemical parameters in whole blood to assess liver function. ${ }^{*} p<0.05$ compared between weeks at the same concentration.
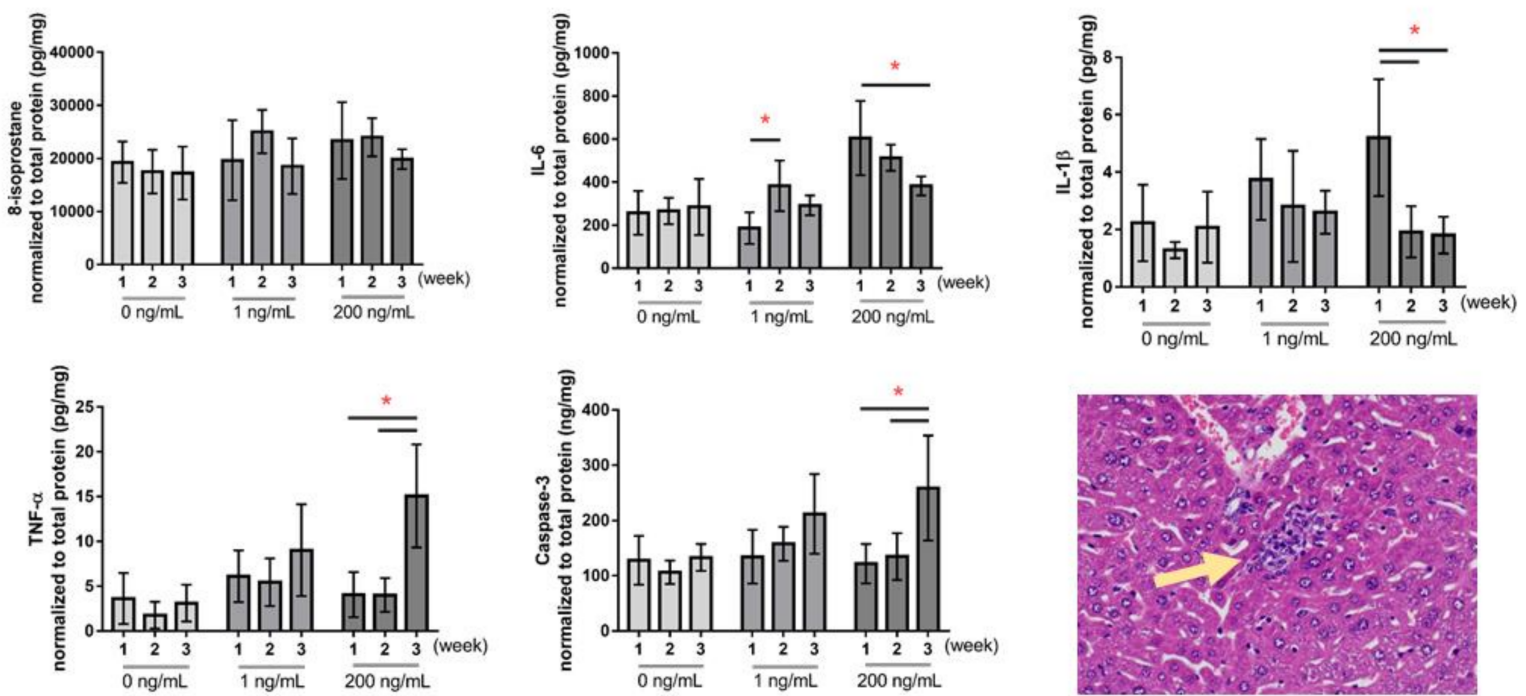

Figure 5. Levels of 8-isoprostane, interleukin (IL)-6, IL-1 $\beta$, tumor necrosis factor (TNF)- $\alpha$, and caspase-3 in the liver after vinyl chloride (VC) exposure. Liver inflammatory infiltration occurred after exposure to $200 \mathrm{ng} / \mathrm{mL}$ VC for 3 weeks (400X). ${ }^{*} p<0.05$ compared between weeks at the same concentration.

\section{Discussion}

Our results indicated that hepatotoxicity occurred due to pulmonary exposure of mice to VC. We first showed that VC adversely affected pulmonary function and increased lung toxicity after 3 weeks of repeated, sub-chronic exposure. Next, liver injury and inflammatory liver infiltration had occurred by 3 weeks of VC exposure. These observations suggest that repeated, sub-chronic exposure to $\mathrm{VC}$ at low levels caused lung and liver toxicity.

VC inhalation is an important occupational health issue in the workplace. The current ACGIH TLV for VC is $1 \mathrm{ppm}$ [11]. However, VC is measurable in the atmosphere in the vicinity of petrochemical complexes [12]. In Taiwan, a previous report indicated that the average concentration was $10.3 \mathrm{ppb}$, and the maximum concentration was $30 \mathrm{ppb}$ in a primary school approximately $1 \mathrm{~km}$ from a petrochemical complex [19]. The World Health Organization (WHO) and EPA California standards for VC are based on the unit risk of liver cancer by life-long VC exposure of $10^{-6} \mu \mathrm{g} / \mathrm{m}^{3}\left(2.5 \times 10^{-6} \mathrm{ppb}\right)$ [22] and a 24-h average concentration of $<10 \mathrm{ppb}$ [23], respectively. To understand the effects of low-level exposure to VC on respiratory and liver systems, a relatively low level of VC $(1 \mu \mathrm{g} / \mathrm{mL}$ $(\mathrm{ppb}))$ and a high level $(200 \mu \mathrm{g} / \mathrm{mL}(\mathrm{ppb}))$ were used for intranasal exposure of mice for 1 to 3 weeks. The exposure level was equal to 1 and $200 \mathrm{mg} / \mathrm{kg}$ of body burden on average. 
For the accumulation dosages, the exposure levels were equal to 15 and $3000 \mathrm{mg} / \mathrm{kg}$ body weight for 3-weeks exposure. We first observed that an increase in the tidal volume and a decrease in the dynamic compliance occurred after VC exposure over 3 weeks. Also, we observed a significant decrease in dynamic compliance with a dose-response manner in the third week after exposure ( $p<0.05$; Supplementary Material Figure S1). The results indicated that more oxygen was required by the body and more carbon dioxide needed to be removed after VC exposure. Changes in the tidal volume suggested that repeated, sub-chronic exposure to VC could impair the function of gas exchange in the lungs. Next, we found that the lungs' ability to stretch and expand had decreased after VC exposure by measuring dynamic lung compliance. A similar observation was reported in a crosssectional study which indicated that significant impairment of lung function occurred in workers employed by petroleum refineries [24]. Taken together, even relatively low levels of VC exposure can cause deterioration of lung function.

It is worth noting that $42 \%$ of inhaled VC may be retained in the lungs [25], highlighting the importance of the lungs as the first target organ that interacts with VC. We observed significant increase in lung permeability, cytotoxicity, oxidative stress, inflammation, and apoptosis in mice lungs after VC exposure, especially after sub-chronic exposure. Also, levels of LDH and IL-6 in BALF and 8-isoprostane, IL-6, and caspase-3 in lung lysates were significantly increased by VC exposure when compared with control in the same week (Supplementary Material Figure S2). Inflammation is a biological response, which seeks to eliminate the initial cause of cell injury and remove necrotic cells and tissues damaged by the original insult and the inflammatory process. Inhaled VC can cause lung epithelial cells to synthesize proinflammatory cytokines and chemokines, which influence local and systemic inflammatory reactions [26]. Such VC-induced lung injury could increase VC levels in circulation, leading to secondary effects on other organs and detoxification organs.

The liver is the detoxification organ in response to exposure to VOCs. Steatosis, inflammation, fibrosis, necrosis, and cancer have been associated with exposure to high VC levels. We observed that AST, ALKP, ALB, and GLOB significantly increased after exposure to VC in mice, whereas the ALB/GLOB ratio significantly decreased after exposure. Also, VC exposure changed the levels of AST, ALKP, ALB, and GLOB, along with the ALB/GLOB ratio, when compared with control in the same week (Supplementary Material Figure S3). The results suggest that VC exposure caused liver injury, liver inflammatory infiltration, and chronic illness and infection of the liver. A study that investigated ALT levels in 261 school-aged children living near a petrochemical complex indicated that ALT was associated with the VC monomer (VCM) biomarker urinary thiodiglycolic acid (TDGA) [27]. Another study, which recruited 251 subjects in 4 VC manufacturing plants, found that VC exposure was associated with increased ALT and AST in workers [28]. The evidence suggests that VC exposure alters liver functions, which involves liver injury. Indeed, we observed that IL-6, IL-1 $\beta$, TNF- $\alpha$, and caspase- 3 increased due to VC exposure in mice. Also, levels of 8 -isoprostane, IL-6, IL-1 $\beta, \mathrm{TNF}-\alpha$, and caspase- 3 were significantly increased by VC exposure when compared with control in the same week (Supplementary Material Figure S4). These observations were also confirmed by liver histology. Similar observations have previously been reported of VC inducing liver injury [29-32]. VC is metabolized to chloroethylene oxide by CYP2EI in the liver [33]. This metabolite spontaneously undergoes rearrangement to form chloroacetaldehyde, or is metabolized to glycolaldehyde by epoxide hydrolase. Chloroacetaldehyde can be further converted to 2-chloroethanol or metabolized to 2-chloroacetic acid by aldehyde dehydrogenase followed by excretion from the body [34]. However, chloroethylene oxide and chloroacetaldehyde are reactive intermediate metabolites that can cause liver injury and DNA damage [35] due to CYP2E1 activity and/or decreased activities of the VC-detoxifying glutathione transferase, epoxide hydrolase, and aldehyde dehydrogenase, thereby increasing the risk of developing VC-induced liver injury.

A few limitations of this study should be noted. Lung toxicity and hepatotoxicity were investigated by sub-chronic and repeated exposure in an in vivo mouse model; the 
effects on humans should be investigated in the future. Sub-chronic and repeated exposure was investigated in the present study; the long-term adverse health effects should be determined in future work. Also, intranasal administration was conducted in this study for VC delivery, which is not the natural route for inhalation exposure. Other chemical components of lung toxicity and hepatotoxicity were not investigated in the present work, but should be studied in the future.

\section{Conclusions}

In conclusion, sub-chronic, repeated exposure to low levels of VC can cause lung and liver toxicity in vivo. Our findings suggest that ambient levels of VC emitted from a petrochemical complex could pose a risk for impairment of the lungs and liver. Therefore, residents living near petrochemical complexes should be aware of the potential health risks.

Supplementary Materials: The following are available online at https:/ / www.mdpi.com/article/10 .3390 /atmos12050596/s1, Figure S1-Alterations in the tidal volume and dynamic compliance of mice after vinyl chloride (VC) exposure. ${ }^{*} p<0.05$ compared between the three concentrations in the same week; Figure S2-Levels of (a) total protein, lactate dehydrogenase (LDH), and interleukin (IL)-6 in bronchoalveolar lavage fluid (BALF) and (b) 8-isoprostane, IL-6, and caspase-3 in the lungs after vinyl chloride (VC) exposure. ${ }^{*} p<0.05$ compared between the three concentrations in the same week; Figure S3 - Levels of biochemical parameters in whole blood to assess liver function. ${ }^{*} p<0.05$ compared between the three concentrations in the same week; Figure S4-Levels of 8-isoprostane, interleukin (IL)-6, IL-1 $\beta$, tumor necrosis factor (TNF)- $\alpha$, and caspase-3 in the liver after vinyl chloride (VC) exposure. Liver inflammatory infiltration occurred after exposure to $200 \mathrm{ng} / \mathrm{mL} \mathrm{VC}$ for 3 weeks. * $p<0.05$ compared between the three concentrations in the same week.

Author Contributions: Data curation, T.-H.Y., J.-H.C., T.-Y.C., C.-H.L. and K.-F.H.; Investigation, H.-C.C.; Writing—original draft, L.-T.C.; Writing—review \& editing, Y.-L.L. All authors contributed substantially to the concept and design of the study, drafting of the article, and critical revision of the manuscript for important intellectual content. All authors have read and agreed to the published version of the manuscript.

Funding: This study was funded by the Ministry of Science and Technology of Taiwan (MOST1042621-M-038-002-MY3).

Institutional Review Board Statement: The study was conducted according to the guidelines of the Declaration of Helsinki, and approved by the ethics review committee of the Laboratory Animal Center (no. LAC-2014-0300) at Taipei Medical University (Taipei, Taiwan).

Informed Consent Statement: Not applicable.

Data Availability Statement: Not applicable.

Acknowledgments: The authors wish to thank Yi-Syuan Lin for technical assistance with this research.

Conflicts of Interest: The authors declare that they have no conflict of interest.

\section{References}

1. Tsai, W.T. An overview of health hazards of volatile organic compounds regulated as indoor air pollutants. Rev. Environ. Health 2019, 34, 81-89. [CrossRef]

2. Tsai, W.-T. Toxic Volatile Organic Compounds (VOCs) in the Atmospheric Environment: Regulatory Aspects and Monitoring in Japan and Korea. Environments 2016, 3, 23. [CrossRef]

3. Chuang, H.C.; Shie, R.H.; Chio, C.P.; Yuan, T.H.; Lee, J.H.; Chan, C.C. Cluster analysis of fine particulate matter (PM2.5) emissions and its bioreactivity in the vicinity of a petrochemical complex. Environ. Pollut. 2018, 236, 591-597. [CrossRef]

4. Koh, D.H.; Chung, E.K.; Jang, J.K.; Lee, H.E.; Ryu, H.W.; Yoo, K.M.; Kim, E.A.; Kim, K.S. Cancer incidence and mortality among temporary maintenance workers in a refinery/petrochemical complex in Korea. Int. J. Occup. Environ. Health 2014, 20, 141-145. [CrossRef]

5. Chen, C.S.; Kuo, T.C.; Kuo, H.C.; Tseng, Y.J.; Kuo, C.H.; Yuan, T.H.; Chan, C.C. Metabolomics of Children and Adolescents Exposed to Industrial Carcinogenic Pollutants. Environ. Sci. Technol. 2019, 53, 5454-5465. [CrossRef] [PubMed]

6. Chiang, T.Y.; Yuan, T.H.; Shie, R.H.; Chen, C.F.; Chan, C.C. Increased incidence of allergic rhinitis, bronchitis and asthma, in children living near a petrochemical complex with $\mathrm{SO} 2$ pollution. Environ. Int. 2016, 96, 1-7. [CrossRef] [PubMed] 
7. Rovira, E.; Cuadras, A.; Aguilar, X.; Esteban, L.; Borras-Santos, A.; Zock, J.P.; Sunyer, J. Asthma, respiratory symptoms and lung function in children living near a petrochemical site. Environ. Res. 2014, 133, 156-163. [CrossRef]

8. Chuang, H.C.; Shie, R.H.; Lee, C.H.; Chio, C.P.; Yuan, T.H.; Lee, J.H.; Chan, C.C. Associations of soluble metals and lung and liver toxicity in mice induced by fine particulate matter originating from a petrochemical complex. Environ. Sci. Pollut. Res. Int. 2020, 27, 34442-34452. [CrossRef] [PubMed]

9. Wang, C.W.; Liao, K.W.; Chan, C.C.; Yu, M.L.; Chuang, H.Y.; Chiang, H.C.; Huang, P.C. Association between urinary thiodiglycolic acid level and hepatic function or fibrosis index in school-aged children living near a petrochemical complex. Environ. Pollut. 2019, 244, 648-656. [CrossRef]

10. IARC. IARC Monographs; World Health Organization: Paris, France, 2018.

11. ACGIH. Threshold Limit Values for Chemical Substances and Physical Agents and Biological Exposure Indices; $\mathrm{ACGIH:} \mathrm{Cincinnati,} \mathrm{OH,}$ USA, 2000.

12. Hsu, Y.C.; Chen, S.K.; Tsai, J.H.; Chiang, H.L. Determination of volatile organic profiles and photochemical potentials from chemical manufacture process vents. J. Air Waste Manag. Assoc. 2007, 57, 698-704. [CrossRef] [PubMed]

13. Anders, L.C.; Lang, A.L.; Anwar-Mohamed, A.; Douglas, A.N.; Bushau, A.M.; Falkner, K.C.; Hill, B.G.; Warner, N.L.; Arteel, G.E.; Cave, M.; et al. Vinyl Chloride Metabolites Potentiate Inflammatory Liver Injury Caused by LPS in Mice. Toxicol. Sci. 2016, 151, 312-323. [CrossRef]

14. Bolt, H.M. Pharmacokinetics of vinyl chloride. Gen. Pharmacol. 1978, 9, 91-95. [CrossRef]

15. Wang, W.; Qiu, Y.L.; Jiao, J.; Liu, J.; Ji, F.; Miao, W.B.; Zhu, Y.; Xia, Z.L. Genotoxicity in vinyl chloride-exposed workers and its implication for occupational exposure limit. Am. J. Ind. Med. 2011, 54, 800-810. [CrossRef] [PubMed]

16. Chiang, S.Y.; Swenberg, J.A.; Weisman, W.H.; Skopek, T.R. Mutagenicity of vinyl chloride and its reactive metabolites, chloroethylene oxide and chloroacetaldehyde, in a metabolically competent human B-lymphoblastoid line. Carcinogenesis 1997, 18, 31-36. [CrossRef]

17. Chang, S.C.; Fedeles, B.I.; Wu, J.; Delaney, J.C.; Li, D.; Zhao, L.; Christov, P.P.; Yau, E.; Singh, V.; Jost, M.; et al. Next-generation sequencing reveals the biological significance of the N (2), 3-ethenoguanine lesion in vivo. Nucleic Acids Res. 2015, 43, 5489-5500. [CrossRef] [PubMed]

18. Chen, Y.M.; Lin, W.Y.; Chan, C.C. The impact of petrochemical industrialisation on life expectancy and per capita income in Taiwan: An 11-year longitudinal study. BMC Public Health 2014, 14, 247. [CrossRef] [PubMed]

19. Chang, B.J. Air Pollutant Emission Control of Major Pollution Sources and Optical Measurement Technology Verification Plan; Taiwan EPA: Taipei, Taiwan, 2017.

20. Chuang, H.C.; Juan, H.T.; Chang, C.N.; Yan, Y.H.; Yuan, T.H.; Wang, J.S.; Chen, H.C.; Hwang, Y.H.; Lee, C.H.; Cheng, T.J. Cardiopulmonary toxicity of pulmonary exposure to occupationally relevant zinc oxide nanoparticles. Nanotoxicology 2014, 8 , 593-604. [CrossRef]

21. Chen, X.Y.; Feng, P.H.; Han, C.L.; Jheng, Y.T.; Wu, C.D.; Chou, H.C.; Chen, Y.Y.; Wu, S.M.; Lee, K.Y.; Kuo, H.P.; et al. Alveolar epithelial inter-alpha-trypsin inhibitor heavy chain 4 deficiency associated with senescence-regulated apoptosis by air pollution. Environ. Pollut. 2021, 278, 116863. [CrossRef]

22. WHO. Air Quality Guidelines for Europe. Available online: https://www.euro.who.int/_data/assets/pdf_file/0013/123070/ AQG2ndEd_5_16vinyl-chloride.pdf (accessed on 1 April 2021).

23. Board Car. Vinyl Chloride \& Health. Available online: https://ww2.arb.ca.gov/resources/vinyl-chloride-and-health (accessed on 1 April 2021).

24. Meo, S.A.; Alrashed, A.H.; Almana, A.A.; Altheiban, Y.I.; Aldosari, M.S.; Almudarra, N.F.; Alwabel, S.A. Lung function and fractional exhaled nitric oxide among petroleum refinery workers. J. Occup. Med. Toxicol. 2015, 10, 37. [CrossRef]

25. Krajewski, J.; Dobecki, M.; Gromiec, J. Retention of vinyl chloride in the human lung. Br. J. Ind. Med. 1980, 37, 373-374. [CrossRef]

26. Ishii, H.; Hayashi, S.; Hogg, J.C.; Fujii, T.; Goto, Y.; Sakamoto, N.; Mukae, H.; Vincent, R.; van Eeden, S.F. Alveolar macrophageepithelial cell interaction following exposure to atmospheric particles induces the release of mediators involved in monocyte mobilization and recruitment. Respir. Res. 2005, 6, 87. [CrossRef]

27. Wang, C.W.; Chuang, H.Y.; Liao, K.W.; Yu, M.L.; Dai, C.Y.; Chang, W.T.; Tsai, C.H.; Chiang, H.C.; Huang, P.C. Urinary thiodiglycolic acid is associated with increased risk of non-alcoholic fatty liver disease in children living near a petrochemical complex. Environ. Int. 2019, 131, 104978. [CrossRef] [PubMed]

28. Cheng, T.J.; Huang, M.L.; You, N.C.; Du, C.L.; Chau, T.T. Abnormal liver function in workers exposed to low levels of ethylene dichloride and vinyl chloride monomer. J. Occup. Environ. Med. 1999, 41, 1128-1133. [CrossRef] [PubMed]

29. Wang, Q.; Zhang, L.; Chen, S.Q.; Ma, W.Y.; Guo, Y.L.; Gao, Y.; Tian, F.J.; Qiu, Y.L. Role of endoplasmic reticulum stress and oxidative stress in vinyl chloride-induced hepatic steatosis in mice. Toxicol. Appl. Pharmacol. 2019, 381, 114730. [CrossRef] [PubMed]

30. Lang, A.L.; Krueger, A.M.; Schnegelberger, R.D.; Kaelin, B.R.; Rakutt, M.J.; Chen, L.; Arteel, G.E.; Beier, J.I. Rapamycin attenuates liver injury caused by vinyl chloride metabolite chloroethanol and lipopolysaccharide in mice. Toxicol. Appl. Pharmacol. 2019, 382, 114745. [CrossRef]

31. Qiu, Y.L.; Xu, Z.B.; Wang, Q.; Hu, J.Y.; Zhang, L.; Chen, S.Q.; Lyu, Y.; Wei, C.L.; Yan, X.Y.; Wang, T. Association between methylation of DNA damage response-related genes and DNA damage in hepatocytes of rats following subchronic exposure to vinyl chloride. Chemosphere 2019, 227, 323-328. [CrossRef] 
32. Wahlang, B.; Hardesty, J.E.; Head, K.Z.; Jin, J.; Falkner, K.C.; Prough, R.A.; Cave, M.C.; Beier, J.I. Hepatic Injury Caused by the Environmental Toxicant Vinyl Chloride is Sex-Dependent in Mice. Toxicol. Sci. 2020, 174, 79-91. [CrossRef] [PubMed]

33. Guengerich, F.P.; Kim, D.H.; Iwasaki, M. Role of human cytochrome P-450 IIE1 in the oxidation of many low molecular weight cancer suspects. Chem. Res. Toxicol. 1991, 4, 168-179. [CrossRef]

34. Hefner, R.E., Jr.; Watanabe, P.G.; Gehring, P.J. Preliminary studies on the fate of inhaled vinyl chloride monomer (VCM) in rats. Environ. Health Perspect. 1975, 11, 85-95. [CrossRef]

35. Dosanjh, M.K.; Chenna, A.; Kim, E.; Fraenkel-Conrat, H.; Samson, L.; Singer, B. All four known cyclic adducts formed in DNA by the vinyl chloride metabolite chloroacetaldehyde are released by a human DNA glycosylase. Proc. Natl. Acad. Sci. USA 1994, 91, 1024-1028. [CrossRef] [PubMed] 